\title{
Testicular Seminoma and Peritonitis about One Case at the Yalgado Ouedraogo University Hospital of Ouagadougou
}

\author{
Nayi Zongo ${ }^{1 *}$, Moussa Bazongo ${ }^{1}$, Mamadou Windsouri ${ }^{1}$, Mousa Kaboré1, Edgar Ouangré1, \\ Maurice Zida1, Aimé Sosthène Ouédraogo², Aboubacar Hirrhum Bambara', \\ Augustin Tozoula Bambara', Si Simon Traore', Ahmadou Dem ${ }^{3}$ \\ ${ }^{1}$ Division of General Surgery, Yalgado Ouédraogo University Hospital, Ouagadougou, Burkina Faso \\ ${ }^{2}$ Division of Pathologic Anatomy, Yalgado Ouédraogo University Hospital, Ouagadougou, Burkina Faso \\ ${ }^{3}$ Oncology Institue Joliot Curie, Dakar, Senegal \\ Email: *nayizongo@yahoo.fr
}

Received 2 November 2015; accepted 15 December 2015; published 18 December 2015

Copyright (C) 2015 by authors and Scientific Research Publishing Inc.

This work is licensed under the Creative Commons Attribution International License (CC BY). http://creativecommons.org/licenses/by/4.0/

(c) (i) Open Access

\begin{abstract}
Introduction: Testicular seminoma is a highly lymphophilic germ cell tumor. It is the most common germ cell tumor in young adults. We are reporting one case of testicular seminoma complicated with an acute generalized peritonitis (AGP), in order to describe the circumstances of diagnosis and discuss about treatment. Observation: It involved a 39-year-old patient, admitted for vague abdominal pains that were evolving since 72 hours with a history of right orchiectomy because of testicular seminoma in 2011. The analysis revealed a peritoneal syndrome, a right inguinal lymphadenopathy of $10 \mathrm{~cm}$ diameter and an empty right scrotum. The exploration revealed fistulized necrotic retro-peritoneal lymphadenopathies in the peritoneal cavity and ileal perforation on contact with these lymphadenopathies. Necrosectomy and ileal resections were performed. After the operation, the scanner revealed a conglomeration of retro-peritoneal adenomegalies extending to the right femoral region associated with bilateral pleurisy. The $\beta$-HCG and the LDH were $8000 \mathrm{IU} / \mathrm{L}$ and $24,500 \mathrm{IU} / \mathrm{L}$, respectively. The seminoma was ranked T3N3M1. The immediate post-operative care was uneventful. The patient was lost from sight for a month and was readmitted in a context of alteration of his general condition. He died before the end of the pre-chemotherapeutic assessment. Conclusion: Scrotal mass is the usual way of revelation of testicular seminoma. In poorly followed-up cases, exceptional complications such as peritonitis may occur and are direct consequences of poor prognosis.
\end{abstract}

\footnotetext{
${ }^{*}$ Corresponding author.
} 


\section{Keywords}

\section{Seminoma, Testicle, Peritonitis, Treatment, Prognosis}

\section{Introduction}

Testicular cancers represent $1 \%$ of cancers in man. Testicular seminoma is the most common germ cell tumor in young adults [1]. Chemotherapy or post-orchiectomy adjuvant radiotherapy is the reference treatment with curability close to $100 \%$ [2]. It is a highly lymphophilic tumor [3]. The usual complications related to the invasion of retro-peritoneal ganglions are ganglion necrosis and the mass effect [4]. The digestive tract can be directly invaded by proximity [3]. Thus, tumor extension can therefore be for example responsible for lymphoedema of lower limbs, ureterohydronephrosis and intestinal obstruction by compression or invasion [4]. In the literature, the responsibility of testicular seminoma in the appearance of acute generalized peritonitis is rare. In 2002 in Sudan, a case of peritonitis resulting from a necrosis of the intra-abdominal seminoma on testicular cryptorchidism was described [5]. We are reporting our first case, in order to describe the circumstances of diagnosis and discuss about treatment.

\section{Observation}

It involved a 39-year-old patient admitted to the visceral emergency unit on $14^{\text {th }}$ March 2013 for vague abdominal pains evolving since 72 hours. We noted a history of right orchiectomy, because of testicular seminoma performed in 2011. The analysis revealed a peritoneal syndrome, a right orchiectomy scar, a right inguinal lymphadenopathy of $10 \mathrm{~cm}$ diameter and an empty right scrotum. During the emergency laparotomy recommended for acute generalized peritonitis, the exploration revealed fistulized necrotic retro-peritoneal lymphadenopathies in the peritoneal cavity. Was also noted an invasion of the ileal segment on contact with ganglion necrosis. The peritonitis was due to the perforation of this loop. An immediate ileoileal termino terminal anastomosis was performed after Ganglion necrosectomy and ileal resection.

A posteriori, the diagnosis of acute generalized peritonitis by ileal perforation resulting from a tumor invasion of a seminoma was retained. The immediate postoperative care was uneventful. The assessment was completed after the emergency. The abdominal and pelvic scan made one week before the operation highlighted inguinal and retroperitoneal lymphadenopathies (Figure 1, Figure 2) associated a bilateral pleurisy (Figure 3) beta chorionic gonadotropin hormones $(\beta$-HCG) and lactate dehydrogenase (LDH) were $8000 \mathrm{IU} / \mathrm{L}$ and 24,500 IU/L, respectively. The seminoma was ranked T3N3M1. The patient was lost from sight for a month and was readmitted in a context of alteration of his general condition. He died before the end of the pre-chemotherapeutic assessment.

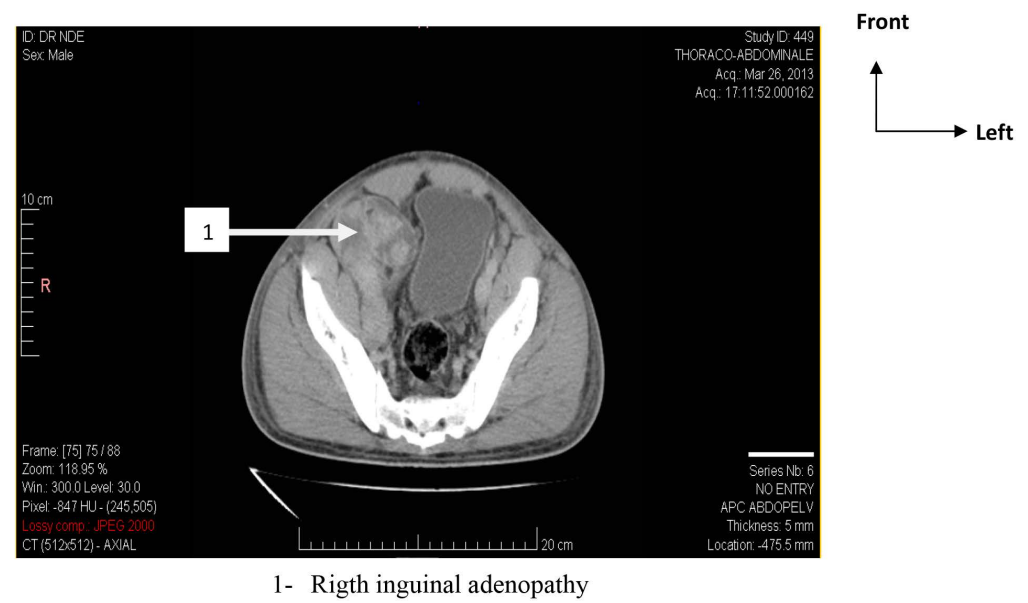

Figure 1. Right inguinal adenopathy with areas of necrosis. 


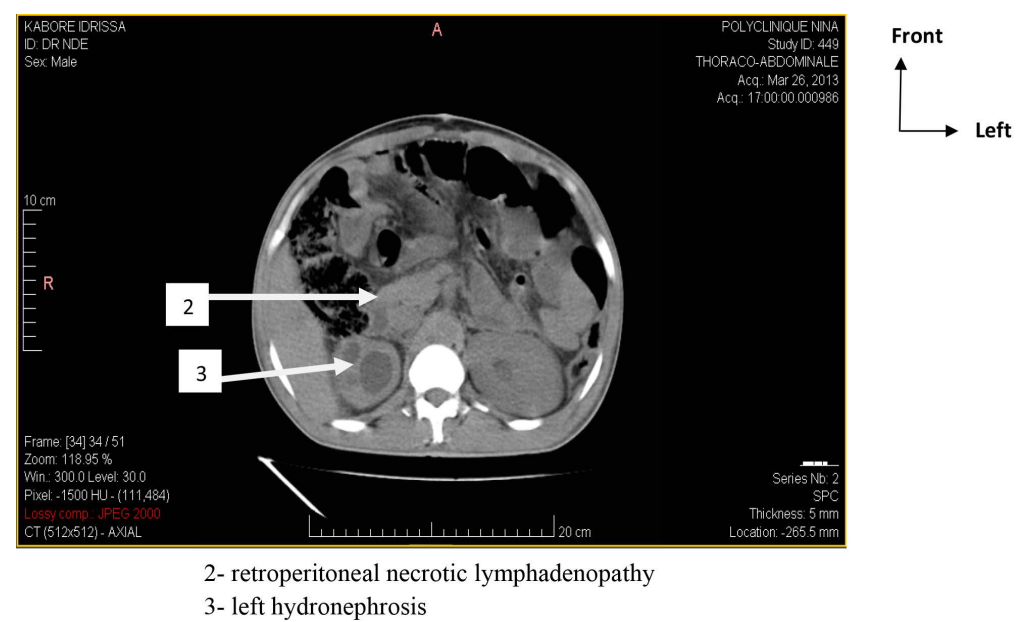

Figure 2. Necrotic lymph nodes below diaphragmatic and right hydronephrosis.

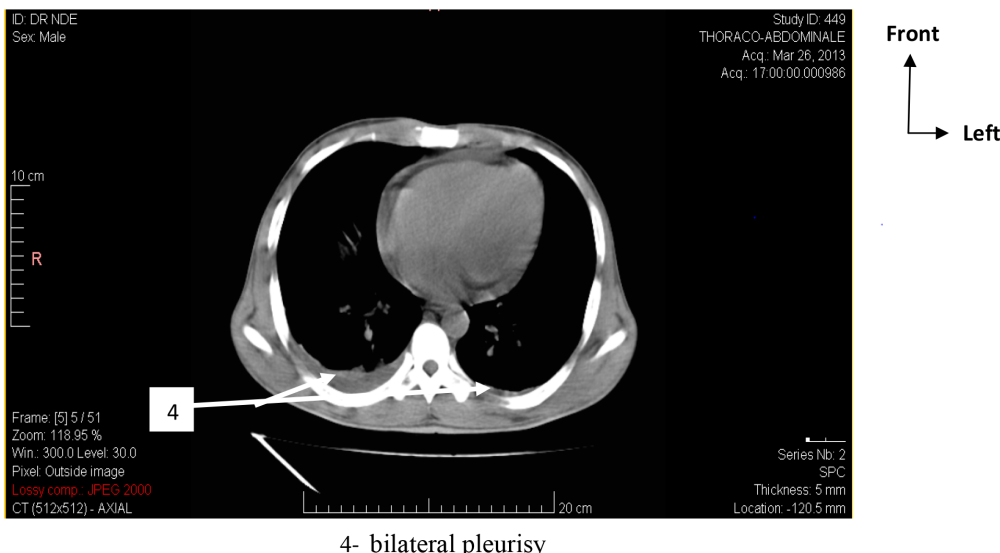

Figure 3. Minimal bilateral pleurisy.

\section{Discussion}

Testicular seminoma is the most common malignant germ cell tumour in young adults [1]. Its ganglion extension is made successively towards the inguinal, iliac and retroperitoneal ganglion chains to reach the supradiaphragmatic and cervical lymph nodes [3]. Testicular mass is the usual circumstance of discovery. Concerning the extra-digestive signs, a ganglion metastasis can be the way of discovery. This was the case in the study by Tazi et al. [6] where a left supra-clavicular lymphadenopathy (TROISIER) enabled diagnose a testicular tumor. Nguyen et al. [7] noted cerebral and splenic metastases as circumstances of diagnosis. The discovery of a testicular seminoma in the etiologic search for digestive manifestations was described. Thus, in the study of Felix et al. [4], a retroperitoneal bilobed cystic mass which was responsible for the appendicular syndrome in 19-yearold young man enabled discover primary testicular tumor. In the same connection, Wehrschültz et al. [8] had diagnosed testicular tumour in the assessment of a cholestatic ictera by tumor invasion of the pancreas. Further cases of acute intestinal obstruction by tumor invasion of the small bowel were described [9]. Ali et al. reported a case of peritonitis resulting from a necrosis of the intra-abdominal seminoma in an undescended testicle [5]. However, an acute generalized peritonitis by ileal perforation resulting from a invasive seminoma like in our case is rarely reported in the literature. This situation must have been favoured by a natural evolution of a seminoma which was treated neither by chemotherapy nor by radiotherapy. Only a diagnostic orchiectomy was performed. These manifestations show in general an advanced phase of primary tumor, so a complicated form and thus occasion therapeutic difficulties. In our study, the lack of post-orchiectomy adjuvant treatment was a determining factor in the occurrence of acute generalized peritonitis. According to the literature, the ideal treatment of complicated forms is based on chemotherapy associating Bleomycin, Etoposide and Cisplatin (BEP 
protocol) for 3 to 4 cycles [10]. Surgery can be recommended for the removal of any post-chemotherapy persistent residual mass [10]. In our study, before the emergency of abdominal surgery, we first of all treated peritonitis and perforation. Later, we proposed chemotherapy which could not be afforded by the patient. However the introduction of social security in favour of the entire population could enable better access of patients to quality care. Testicular seminoma is reputed to be a cancer of good prognosis even when metastatic. As evidence in the study by Wehrschültz et al. [8] and Nguyen et al. [7], the good evolution with a complete decrease of the symptoms with no recurrence after two years in their patients who were at a metastatic phase (pancreas, spleen, brain) of their testicular germ cell tumors. In our case, the prognosis of the patient was somber because not only of the advanced stage of the disease but also the desperate evolution of an acute generalized peritonitis occurring in a patient who was already weakened. Furthermore, the lack of specific treatment with chemotherapy was a factor of mortality. Improved prognosis goes through an early diagnosis of testicular seminoma, an adjuvant treatment after orchiectomy and a careful oversight.

\section{Conclusion}

Scrotal mass is the common way of revelation of testicular seminoma. Acute generalized peritonitis by ileal perforation by invasive seminoma remains an exceptional and serious complication. It requires surgical treatment on a weakened patient. The prognosis of this association is bad.

\section{References}

[1] Hachi, H., Bouzidi, A., Bougtab, A., Ottmany, A., Baroudi, C., Tijami, F., et al. (1996) Le séminome spermatocytaire: A propos d'un cas et revue de la littérature. Médecine du Maghreb, 60, 6-8.

[2] Langlois, C., Danzon, A., Kieffer, Y., Cléro, E. and Bontemps, P. (2005) Séminome testiculaire et risque de 2ème cancer dans le département du Doubs, Registre des tumeurs du Doubs. CHU Besançon, France, 37.

[3] Thoumas, D., Caty, A., Gobet, F. and Lemaitre, L. (2002) Imagerie des tumeurs du testicule. Journal de Radiologie, 83, 883-893.

[4] Félix, L., Bricault, I., Stéfani, L., Risse, O., Terrier, N., Ringeisen, F. and Ferretti, G. (2008) Un cancer du testicule révélé par un syndrome appendiculaire et une tumeur kystique rétro péritonéale. Journal de Radiologie, 89, 813-816. http://dx.doi.org/10.1016/S0221-0363(08)73790-9

[5] Ali, A.L.K.E., Toum, F.E.M. and Magzoub, M. (2012) Case Report: Peritonitis Secondary to Necrosis of Intra-Abdominal Seminoma in an Undescended Testis. Kassala University Journal, 2, 7-10.

[6] Tazi, M.F., Riyach, O., Ahsaini, M., Ahallal, Y., Khallouk, A., Fassi, M.J.E. and Farih, M.H. (2013) Tumor in Undescended Intrapelvic Testis Revealed by Supraclavicular Lymphadenopathy: A Case Report and Literature Review. BMC Research Notes, 6, 166. http://dx.doi.org/10.1186/1756-0500-6-166

[7] Nguyen, M.M., Corr, A.N.S. and Evans, C.P. (2004) Testicular Cancer Metastatic Exclusively to the Brain and Spleen. Urology, 63, 176-176. http://dx.doi.org/10.1016/j.urology.2003.08.021

[8] Wehrschütz, M., Stöger, H., Ploner, F., Hofmann, G., Wolf, G., Höfler, G., Krippl, P. and Samonigg, H. (2002) Seminoma Metastases Mimicking Primary Pancreatic Cancer. Onkologie, 25, 371-373. http://dx.doi.org/10.1159/000066057

[9] Idelevich, E., Kashtan, H., Mavor, E. and Brenner, B. (2006) Small Bowel Obstruction Caused by Secondary Tumors. Surgical Oncology, 15, 29-32. http://dx.doi.org/10.1016/j.suronc.2006.05.004

[10] Duranda, X., Rigauda, J., Avancèsa, C., Camparoa, P., Fléchona, A., Mureza, T., Sèbea, P., Culineb, S., Iborrab, F., Mottetb, N., Colobyb, P., Soulié, M., et les membres du CCAFU (2013) Recommandations en oncourologie 2013 du CCAFU: Tumeurs germinales du testicule. Progrès en Urologie, 2013, S145-S160. http://dx.doi.org/10.1016/S1166-7087(13)70052-6 